\title{
The second Residential Scientific Conference for Senior Registrars in Psychiatry*
}

\author{
O. JUNAID, Academic Senior Registrar in Psychiatry, Mapperley Hospital, \\ Nottingham NG3 6AA; Chairman, Collegiate Trainees' Committee
}

\begin{abstract}
About 70 senior registrars from the United Kingdom and the Republic of Ireland spent a weekend at the Manchester Business School. The weekend started with a 'keynote' address by Professor John Wing on Measuring Psychiatric Morbidity: symptoms, diagnosis, handicaps, needs and outcomes. This lecture introduced us to the conceptual issues surrounding the ICD-10 classification and the need for sensitive and valid research criteria and instruments.

Saturday was devoted to workshop sessions. There were day-long workshops on computer skills for psychiatrists, presentation skills and witness skills. Participants had hands-on experience and learnt how to use the computer to perform statistical analysis, and utilise data-base and spreadsheet functions as well as improve word-processing skills. The presentation skills workshop produced a personal video to take back of one's performance enabling the learning process to continue long after the end of the weekend. The witness skills experiential workshop proved useful to all who attended providing the opportunity of improving presentation skills in the courtroom.
\end{abstract}

There were half-day workshops on management skills, medical ethics and research methodology with

*Held at the Manchester Business School, April 1991. management skills proving the most popular of the workshops. Dr Greg Richardson, Consultant Child Psychiatrist, Limetrees Adolescent Unit, York, conducted a workshop entitled 'Managing your first day as a consultant'. The workshop was an eye-opener and very useful. The details of the workshop would be well worth filing and referring to prior to interview, on starting the new job and a few years into the job! Professor Patricia Casey, just two weeks in her 'Chair', led the research methodology workshop. Participants presented a large number of actual and potential hurdles in the planning, execution and publication of a research project. The approach was problem orientated but did look towards producing good quality research. The major aspect covered was the choice of topic such as a specific and defined problem to be addressed to which an answer could be found which would enlarge patient knowledge and affect practice.

Professor Sheila Hollins spoke on "Generic or specialist services for children and adults with mental handicap and mental illness'. This was by far the most controversial of the presentations and certainly challenged our basic assumptions on our own individual training needs and also our assumptions on the type of service that we as general adult and specialist psychiatrists will provide in a sector-based service.

\section{Reduced subscriptions}

The International Journal of Psycho-Analysis and the International Review of Psycho-Analysis are offering subscriptions at a reduced rate to members of organisations wishing to subscribe through their societies as block subscribers: $£ 43$ for Journal, $£ 40$ for Review, $£ 75$ for combined subscription. The appropriate amount should be sent to Mrs Jean Wales at the College (cheque made payable to the Royal College of Psychiatrists) by not later than 2 November 1991. 